\title{
Mechanisms on the Injection Conformance Reversion during Polymer Flooding of Offshore Heterogeneous Heavy- Oil Reservoirs
}

\author{
Zhijie Wei $\mathbb{D}^{1,2}$ Xiaodong Kang, ${ }^{1,2}$ Yuyang Liu, ${ }^{1,2}$ and Hanxu Yang ${ }^{1,2}$ \\ ${ }^{1}$ State Key Laboratory of Offshore Oil Exploitation, Beijing 100028, China \\ ${ }^{2}$ CNOOC Research Institute Co. Ltd., Beijing 100028, China \\ Correspondence should be addressed to Zhijie Wei; weizhj5@cnooc.com.cn
}

Received 8 November 2020; Revised 23 December 2020; Accepted 4 January 2021; Published 21 January 2021

Academic Editor: Guanglong Sheng

Copyright (C) 2021 Zhijie Wei et al. This is an open access article distributed under the Creative Commons Attribution License, which permits unrestricted use, distribution, and reproduction in any medium, provided the original work is properly cited.

\begin{abstract}
Injection conformance reversion commonly observed during polymer flooding in offshore heterogeneous heavy-oil reservoirs weakens the volumetric sweep of polymer solution and compromises its EOR results. To investigate its mechanisms and impact factors, one mathematical model to predicate injection conformance behavior is constructed for heterogeneous reservoirs based on the Buckley-Leverett function. The different suction capability of each layer to polymer solution results in distinct change law of the flow resistance force, which in turn reacts upon the suction capability and creates dynamic redistribution of injection between layers. Conformance reversion takes place when the variation ratio of flow resistance force of different layers tends to be the same. The peak value and scope of conformance reversion decrease and reversion timing is advanced as oil viscosity or permeability contrast increases, or polymer concentration or relative thickness of low permeable layer decreases, which compromises the ability of polymer flooding to improve the volumetric sweep and lower suction of the low permeable layer. The features of offshore polymer flooding tend to make the injection conformance V-type and create low-efficiency circulation of polymer in a high permeable layer more easily. These results can provide guidance to improve the production performance of polymer flooding in offshore heterogeneous heavy-oil reservoirs.
\end{abstract}

\section{Introduction}

Polymer flooding is proved as one successful EOR technology in offshore oilfields of Bohai Bay, China $[1,2]$. It has the characteristics of large permeability contrast for multilayer injection, high viscosity of crude oil, and earlier polymer flooding start-up [3-5]. However, some production wells witness adverse performance, such as early water cut rebound, high produced polymer concentration, and fast growth, which compromise EOR results of polymer flooding [6-8]. It is found that it is subject to the conformance reversion induced by the conventional single-slug continuous polymer injection pattern [9-11], which indicates that the relative suction amount of the low permeable zone firstly increases and then decreases during polymer flooding. After that, the vertical sweep is continuously weakened, which leads to low-efficiency circulation of polymer solution in the high permeable zone [12-14]. It is necessary to contain the conformance reversion to further improve EOR results of polymer flooding.

At present, researches related to conformance reversion mainly focus on late polymer flooding scenarios and light oil reservoir with medium viscosity [9-11], which is not the case for offshore polymer flooding. Moreover, current researches highlight the inhibition or control methods of conformance reversion [13-16]. However, analysis of conformance reversion itself and especially induction mechanisms need to be further carried out. In addition, the laboratory experiment method is usually utilized to explore its mechanisms $[7,9,11]$, which is time-consuming, has a high cost, and is easily affected by human factors, and limited impact factors are under investigation. There is a lack of a mathematical model for rapid quantitative characterization of conformance reversion. Hence, one mathematical model 
of the injection conformance of offshore heterogeneous heavy-oil reservoir is proposed in this study; the mechanisms and its change law on the conformance reversion during polymer flooding are explored. In addition, key factors of the conformance reversion are investigated.

\section{Injection Conformance Mathematical Model of Heterogeneous Heavy-Oil Reservoir}

2.1. Injection Conformance Equations. As for a multilayer heterogeneous reservoir, the volumetric injection rate of each layer can be expressed as

$$
q_{i}=\alpha \frac{K_{i} H_{i} W_{i}}{\bar{\lambda}_{i}^{-1}} \nabla p
$$

where $q$ is volumetric injection rate, $\mathrm{m}^{3} / \mathrm{s} ; K$ is permeability, $10^{-3} \mu \mathrm{m}^{2} ; p$ is pressure, $\mathrm{MPa} ; H$ is effective thickness, $\mathrm{m} ; W$ is the distance between injectors, $\mathrm{m} ; \bar{\lambda}_{i}^{-1}$ is apparent viscosity of layer $i$, which represents the average viscosity between the injector and producer, $\mathrm{mPa} \cdot \mathrm{s}$; $\alpha$ is the unit conversion factor, $10^{-6} ; \nabla$ is the gradient operator; and the subscript $i$ is the layer number.

According to Eq. (1), the relative liquid injection of each layer is

$$
f_{i}=\frac{q_{i}}{\sum q_{i}}=K_{i} H_{i} / \bar{\lambda}_{i}^{-1} / \sum K_{i} H_{i} / \bar{\lambda}_{i}^{-1}
$$

As the permeability $K$ and effective thickness $H$ are known, the apparent viscosity $\bar{\lambda}_{i}^{-1}$ is the key to calculate the relative liquid injection.

Injection pore volume coefficient $Q_{i}$ is introduced, which is defined as the ratio of the cumulative injection volume to the pore volume of each layer (PV). Then, the volumetric injection rate of each layer can be written as

$$
\begin{gathered}
q_{i}=V_{\mathrm{PV}, i} \cdot \frac{d Q_{i}}{d t}, \\
V_{\mathrm{PV}, i}=H_{i} W_{i} L_{i} \phi_{i},
\end{gathered}
$$

where $V_{\mathrm{PV}, i}$ is pore volume of layer $i, \mathrm{~m}^{3} ; L$ is the distance between the injector and the producer, $\mathrm{m} ; \phi_{i}$ is porosity of layer $i$; and $t$ is time, s.

It can be obtained by rearranging Eqs. (1) and (3):

$$
\bar{\lambda}_{i}^{-1} \frac{d Q_{i}}{d t}=\frac{K_{i}}{\phi_{i} L} \frac{\Delta p}{L} \text {. }
$$

Then, the apparent viscosity between layers $i$ and $j$ satisfies

$$
\frac{\bar{\lambda}_{j}^{-1} d Q_{j}}{\bar{\lambda}_{i}^{-1} d Q_{i}}=\frac{K_{j}}{K_{i}} \frac{\phi_{i}}{\phi_{j}}, \quad j \neq i
$$

2.2. Apparent Viscosity Equations. The apparent viscosity $\bar{\lambda}_{i}^{-1}$ indicates the difficulty of fluid flow between the injector and the producer. The larger its value, the larger the flow resistance and the smaller the flow ability.

According to the definition, the apparent viscosity is written as

$$
\bar{\lambda}_{i}^{-1}=\frac{\int_{0}^{L}\left(1 / \lambda_{T}\right)_{i} d x}{\int_{0}^{L} d x}=\frac{\int_{0}^{L}\left(1 /\left(\lambda_{\mathrm{w} / \mathrm{p}}+\lambda_{\mathrm{o}}\right)\right)_{i} d x}{L}
$$

where $\lambda_{T}$ is the total mobility of liquid, $(\mathrm{mPa} \cdot \mathrm{s})^{-1}$, and the subscripts $\mathrm{w}, \mathrm{p}$, and $\mathrm{o}$ are water, polymer, and oil, respectively.

According to the fluid flow theory in porous media and the Buckley-Leverett function [17-19], the equation of the apparent viscosity of each layer is derived, respectively, for the stages of water flooding, polymer flooding, and chase water flooding in the following.

2.2.1. Water Flooding Stage. According to the BuckleyLeverett function, the continuity equation of the water flooding stage is

$$
d x_{i}=L Q_{i} d f_{\mathrm{w}, i}^{\prime}
$$

where $f_{\mathrm{w}, i}$ is water cut of layer $i$ and $f_{\mathrm{w}, i}^{\prime}$ is the partial derivation of $f_{\mathrm{w}, i}$ to water saturation $S_{\mathrm{w}, i}$.

Given the relative permeability curves and liquid viscosities, the total mobility of oil and water is a function of water saturation $S_{\mathrm{w}, i}$, i.e., $\lambda_{T, i}=\lambda_{\mathrm{w}, i}+\lambda_{\mathrm{o}, i}=g\left(S_{\mathrm{w}, i}\right)$, and in the injected water swept region, the partial derivation $f_{\mathrm{w}, i}^{\prime}$ is a monotone function of water saturation $S_{\mathrm{w}, i}$, i.e., $f_{\mathrm{w}, i}^{\prime}=h\left(S_{\mathrm{w}, i}\right)$, then $S_{\mathrm{w}, i}=h^{-1}\left(f_{\mathrm{w}, i}^{\prime}\right)$. In general, total mobility can be expressed as the function of $f_{\mathrm{w}, i^{*}}^{\prime}$

$$
\lambda_{T, i}=g\left(S_{\mathrm{w}, i}\right)=g\left(h^{-1}\left(f_{\mathrm{w}, i}^{\prime}\right)\right)=m\left(f_{\mathrm{w}, i}^{\prime}\right)
$$

If the injected water has broken through, Eqs. (8) and (9) are substituted into Eq. (7):

$\bar{\lambda}_{i}^{-1}=Q_{i} \cdot \int_{0}^{L} \frac{1}{m\left(f_{\mathrm{w}, i}^{\prime}\right)} d f_{\mathrm{w}, i}^{\prime}=Q_{i} \cdot \int_{0}^{1 / Q_{i}} \frac{1}{m\left(f_{\mathrm{w}, i}^{\prime}\right)} d f_{\mathrm{w}, i}^{\prime}=n\left(Q_{i}\right)$.

If the injected water has not broken through, the leading edge position of the injected water is $x_{\mathrm{wf}, i}=L Q_{i} f_{\mathrm{wf}, i} ;$ it is substituted into Eq. (7):

$$
\bar{\lambda}_{i}^{-1}=\mu_{\mathrm{o}}+Q_{i}\left(\int_{0}^{f_{\mathrm{wf}, i}^{\prime}} \frac{1}{m\left(f_{\mathrm{w}, i}^{\prime}\right)} d f_{\mathrm{w}, i}^{\prime}-\mu_{\mathrm{o}} f_{\mathrm{wf}, i}^{\prime}\right)
$$

where $f_{\mathrm{wf}, i}$ is the partial derivation of water cut at the leading edge position of the injected water. According to the BuckleyLeverett function, $f_{\mathrm{wf}, i}^{\prime}$ is ascertainable at the given relative 
permeability curves and liquid viscosities, and $\int_{0}^{f_{\mathrm{wf}, i}^{\prime}}(1 / m$ $\left.\left(f_{\mathrm{w}, i}^{\prime}\right)\right) d f_{\mathrm{w}, i}^{\prime}$ is ascertainable accordingly.

Based on Eqs. (9) and (10), the apparent viscosity $\bar{\lambda}_{i}^{-1}$ is only related to the injection pore volume coefficient $Q_{i}$.

2.2.2. Polymer Flooding Stage. A polymer is a chemical compound with big molecules, and there is some space that polymer cannot access in the porous media, which is defined as the inaccessible pore volume number IPV [20-22], which is not the case for water, and there is no inaccessible pore volume.

Similar to water flooding (Eq. (8)), the continuity equation during the polymer flooding stage can be derived by additionally considering the IPV, and its expression is

$$
d x_{i}=\frac{L Q_{i}}{1-\mathrm{IPV}_{i}} d f_{\mathrm{p}_{, i}}^{\prime} .
$$

A polymer has the effect of increasing the viscosity of the aqueous phase and decreasing its effective permeability induced by adsorption or retention. Therefore, the total mobility of the polymer swept region is different from that of water, i.e.,

$$
\lambda_{T, i}=\left(\frac{k_{\mathrm{rw}}}{R_{k} \mu_{\mathrm{p}}}+\frac{k_{\mathrm{ro}}}{\mu_{\mathrm{o}}}\right),
$$

where $\lambda$ is mobility, $(\mathrm{mPa} \cdot \mathrm{s})^{-1} ; k_{\mathrm{r}}$ is relative permeability; $\mu$ is viscosity, $\mathrm{mPa} \cdot \mathrm{s}$; and $R_{k}$ is residual resistance factor, denoting the degree of permeability reduction due to polymer adsorption.

Accordingly, the water cut $f_{p, i}$ of the polymer swept zone in layer $i$ :

$$
f_{\mathrm{p}, i}=\left(\frac{\lambda_{\mathrm{p}}}{\lambda_{\mathrm{p}}+\lambda_{\mathrm{o}}}\right)_{i}=\left[\frac{k_{\mathrm{rw}} /\left(R_{k} \mu_{\mathrm{p}}\right)}{k_{\mathrm{rw}} /\left(R_{k} \mu_{\mathrm{p}}\right)+k_{\mathrm{ro}} / \mu_{\mathrm{o}}}\right]_{i}
$$

Referring to the water flooding stage, the apparent viscosity of the polymer flooding stage is the function of the injection pore volume coefficient of the water flooding stage $Q_{\mathrm{w}, i}$ and that of the polymer flooding $Q_{p, i}$, i.e.,

$$
\left\{\begin{array}{l}
\bar{\lambda}_{i}^{-1}=\int_{0}^{L}\left(\frac{1}{\lambda_{\mathrm{w} / \mathrm{p}}+\lambda_{\mathrm{o}}}\right)_{i} d x_{i}=\int_{0}^{L_{\mathrm{p}, i}}\left(\frac{1}{\lambda_{\mathrm{p}}+\lambda_{\mathrm{o}}}\right)_{i} d x_{i}+\int_{L_{\mathrm{p}, i}}^{L}\left(\frac{1}{\lambda_{\mathrm{w}}+\lambda_{\mathrm{o}}}\right)_{i} d x_{i}, \\
x_{i}= \begin{cases}L \cdot \frac{Q_{\mathrm{p}, i}}{1-\mathrm{IPV}_{i}} \cdot f_{\mathrm{p}, i}^{\prime}\left(S_{\mathrm{p}, i}\right), & x \in\left[0, L_{\mathrm{p}, i}\right], \\
L \cdot\left(Q_{\mathrm{w}, i}+Q_{\mathrm{p}, i}\right) \cdot f_{\mathrm{w}, i}^{\prime}\left(S_{\mathrm{w}, i}\right), & x \in\left[L_{\mathrm{p}, i}, L\right] .\end{cases}
\end{array}\right.
$$

The leading edge position of the injected polymer is

$$
L_{\mathrm{p}, i}=L \cdot \frac{Q_{\mathrm{p}, i}}{1-\mathrm{IPV}_{i}} \cdot f_{\mathrm{pf}, i}^{\prime}
$$

where $f_{\mathrm{pf}, i}^{\prime}$ is the partial derivation of $f_{\mathrm{p}, i}$ to polymer solution saturation $S_{\mathrm{p}, i}$ in the polymer swept zone.

2.2.3. Chase Water Flooding Stage. The apparent viscosity of the chase water flooding stage is the function of the injection pore volume coefficient of the water flooding stage $Q_{\mathrm{w}, i}$, that of the polymer flooding stage $Q_{\mathrm{p}, i}$, and that of the chase water flooding stage $Q_{\mathrm{w} 2, i}$, i.e.,

$\left\{\begin{array}{l}\bar{\lambda}_{i}^{-1}=\int_{0}^{L_{\mathrm{w} 2, i}}\left(\frac{1}{\lambda_{\mathrm{w} 2}+\lambda_{\mathrm{o}}}\right)_{i} d x_{i}+\int_{L_{\mathrm{w} 2, i}}^{L_{\mathrm{p}, i}}\left(\frac{1}{\lambda_{\mathrm{p}}+\lambda_{\mathrm{o}}}\right)_{i} d x_{i}+\int_{L_{\mathrm{p}, i}}^{L}\left(\frac{1}{\lambda_{\mathrm{w} 1}+\lambda_{\mathrm{o}}}\right)_{i} d x_{i}, \\ x_{i}= \begin{cases}L \cdot Q_{\mathrm{w} 2, i} \cdot f_{\mathrm{w} 2, i}^{\prime}\left(S_{\mathrm{w}, i}\right), & x \in\left[0, L_{\mathrm{w} 2, i}\right], \\ L \cdot\left(Q_{\mathrm{w} 2, i}+\frac{Q_{\mathrm{p}, i}}{1-\mathrm{IPV}_{i}}\right) \cdot f_{\mathrm{p}, i}^{\prime}\left(S_{\mathrm{p}, i}\right), & x \in\left[L_{\mathrm{w} 2, i} L_{\mathrm{p}, i}\right], \\ L \cdot\left(Q_{\mathrm{w} 2, i}+Q_{\mathrm{p}, i}+Q_{\mathrm{w} 1, i}\right) \cdot f_{\mathrm{w} 1, i}^{\prime}\left(S_{\mathrm{w}, i}\right), & x \in\left[L_{\mathrm{p}, i}, L\right],\end{cases} \end{array}\right.$

where the leading edge position of the injected polymer $L_{\mathrm{p}, i}$ and that of the chase water flooding stage $L_{\mathrm{w} 2, i}$ are

$$
\left\{\begin{array}{l}
L_{\mathrm{w} 2, i}=L \cdot Q_{\mathrm{w} 2, i} \cdot f_{\mathrm{w} 2 f, i}^{\prime}, \\
L_{\mathrm{p}, i}=L \cdot\left(Q_{\mathrm{w} 2, i}+\frac{Q_{\mathrm{p}, i}}{1-\mathrm{IPV}_{i}}\right) \cdot f_{\mathrm{pf}, i}^{\prime}
\end{array}\right.
$$

To sum up, the apparent viscosity of layer $i$ is only related to its injection pore volume coefficient $Q_{i}$ :

$$
\bar{\lambda}_{i}^{-1}=\int_{0}^{L}\left(\frac{1}{\lambda_{\mathrm{w} / \mathrm{p}}+\lambda_{\mathrm{o}}}\right) d x_{i}=\bar{\lambda}_{i}^{-1}\left(Q_{i}\right) .
$$

2.2.4. Constraints. As the apparent viscosity of layer $i$ is only related to its injection pore volume coefficient $Q_{i}$, it is necessary to calculate the allocation of total injection volume between layers. According to the law of mass conservation, the total injection rate is the sum of the injection rate of each layer:

$q=V_{\mathrm{PV}} \cdot \frac{d Q}{d t}=\sum V_{\mathrm{PV}, i} \frac{d Q_{i}}{d t}=>q d t=V_{\mathrm{PV}} \cdot d Q=\sum V_{\mathrm{PV}, i} d Q_{i}$.

Integrate both sides of Eq. (18) and obtain

$$
\sum V_{\mathrm{PV}, i} \cdot Q_{i}=V_{\mathrm{PV}} \cdot Q=\int_{0}^{t} q d t
$$

2.3. Numerical Solution and Validation. The mathematical model of the injection conformance of an offshore heterogeneous heavy-oil reservoir is proposed in this study, which consists of the injection conformance equation (Eq. (2)), the apparent viscosity equations (Eqs. (10), (11), (15), and (17)), the apparent viscosity equation between layers (Eq. (6)), and constraints (Eq. (21)). According to the above derivation, the relative liquid injection amount of each layer only 
depends on its apparent viscosity, and the apparent viscosity only depends on its injection pore volume coefficient. Thus, it is important to obtain the injection pore volume coefficient of each layer, which can be solved by Eq. (6) and (21):

$$
\left\{\begin{array}{l}
\frac{\int_{0}^{Q_{j}} \bar{\lambda}_{j}^{-1}\left(Q_{j}\right) d Q_{j}}{\int_{0}^{Q_{i}} \bar{\lambda}_{i}^{-1}\left(Q_{i}\right) d Q_{i}}=\frac{K_{j}}{K_{i}} \frac{\phi_{i}}{\phi_{j}}, \quad j \neq i, \\
\sum V_{\mathrm{PV}, i} \cdot Q_{i}=\int_{0}^{t} q d t .
\end{array}\right.
$$

As for the given reservoir, the parameters such as permeability, porosity, pore volume, and injection pore volume coefficient of each layer are known. Besides, the relationship between the apparent viscosity and the injection pore volume coefficient is ascertained by Eqs. (10), (11), (15), and (17), so the indefinite integral term $\int_{0}^{Q_{j}} \bar{\lambda}_{j}^{-1}\left(Q_{j}\right) d Q_{j}$ is a nonlinear function of $Q_{i}$ in Eq. (6). Eq. (20) involves complicated nonlinear solutions, and the direct solution method is difficult and time-consuming, so the Newton-Raphson iterative solution method is adopted. The corresponding numerical solver is developed, whereby the injection pore volume coefficient of each layer at different time can be fast and efficiently obtained and then the apparent viscosity and the relative liquid injection amount are calculated.

The accuracy and reliability of the mathematical model developed are verified by history matching of experimental results. The conditions of two-layer parallel core displacement experiments are as follows: (1) based on the reservoir properties of SZ oilfield in Bohai Sea, some homogeneous long cores with size $4.5 \mathrm{~cm} \times 4.5 \mathrm{~cm} \times 30.0 \mathrm{~cm}$ are artificially made and are saturated with the initial oil saturation of $60 \% \sim 68 \%$; (2) the crude oil and aviation kerosene are mixed into simulated oil with viscosity of $70.0 \mathrm{mPa} \cdot \mathrm{s}$ at 60 degrees Celsius; (3) the relative permeability curves are measured by core flooding under the unsteady state method, and the normalized relative permeability curves are shown in Figure 1; (4) the polymer solution with concentration of $1750 \mathrm{mg} / \mathrm{L}$ and viscosity of $8.0 \mathrm{mPa} \cdot \mathrm{s}$ was prepared by formation water and sewage dilution under the same platform conditions; (5) the overall core flooding processes consist of the water flooding stage, polymer flooding stage, and chase water flooding stage. In the water flooding stage, the water injection rate is $2.0 \mathrm{~mL} / \mathrm{min}$ and the cumulative injection volume is $0.23 \mathrm{PV}$; in the polymer flooding stage, the injection rate is changed to $1.0 \mathrm{~mL} / \mathrm{min}$ and the cumulative injection volume of this stage is $0.50 \mathrm{PV}$; in the chase water flooding stage, the injection rate is $1.0 \mathrm{~mL} / \mathrm{min}$ and the total injection volume is 2.0 PV. Data such as injection, liquid production, and pressure difference between injector and producer are measured in real time during core flooding.

The mathematical model developed is applied to history match the core displacement results, and the comparison indexes include the relative injection amount of each layer and pressure difference between inlet and outlet. The comparison between the calculated results and the lab data is shown in Figures 2 and 3. Simulation results have a good

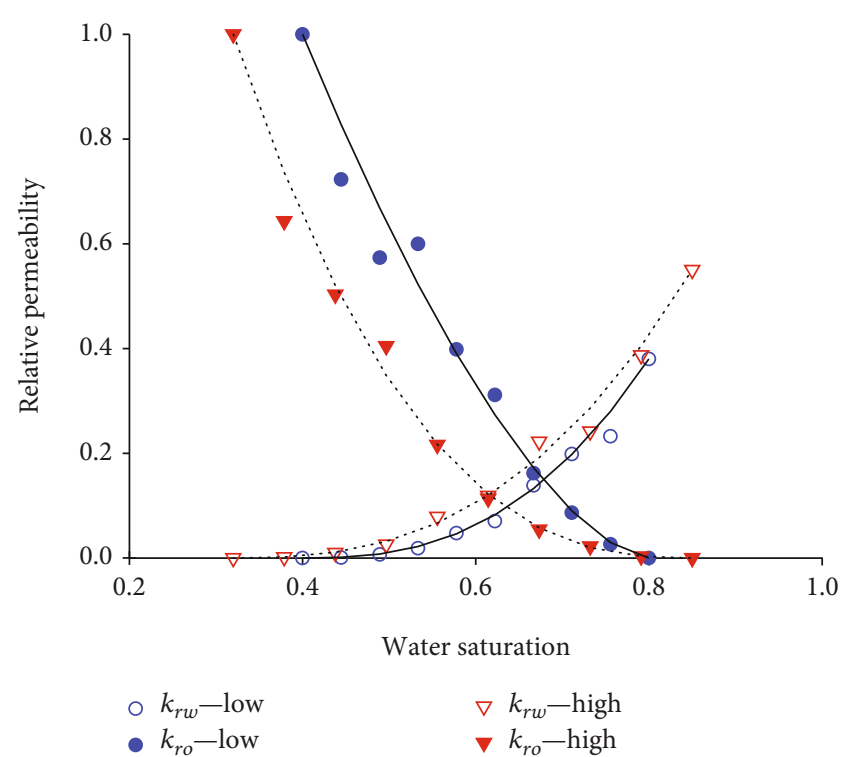

FIgure 1: Relative permeability curves of cores with different permeability.

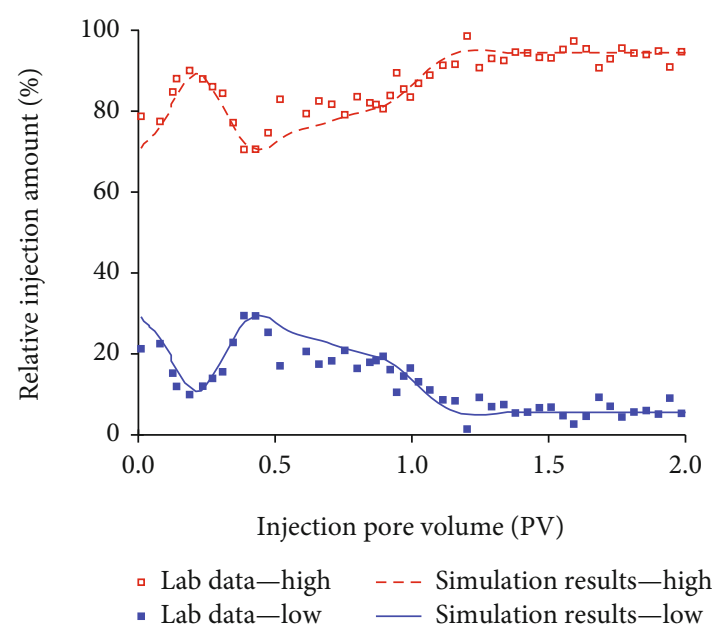

FIgURE 2: Comparison of injection conformance between experiment data and model calculation.

agreement with lab data with the relative deviation less than $5.0 \%$.

\section{Mechanisms and Impact Factor Analysis of Injection Conformance Reversion}

The mathematical model of the injection conformance of an offshore heterogeneous heavy-oil reservoir is applied to explore mechanisms and investigate impact factors of injection conformance reversion. The typical simulation model is established by referring to the reservoir properties of SZ oilfield in Bohai Sea: (1) the reservoir has dual layers with permeability of $500 \times 10^{-3} \mu \mathrm{m}^{2}$ and $2000 \times 10^{-3} \mu \mathrm{m}^{2}$, respectively, and the permeability contrast is 4 ; (2) the determinant well pattern is adopted with well spacing of $300 \mathrm{~m}$ and effective vertical thickness of $15 \mathrm{~m}$; (3) PVT parameters are 


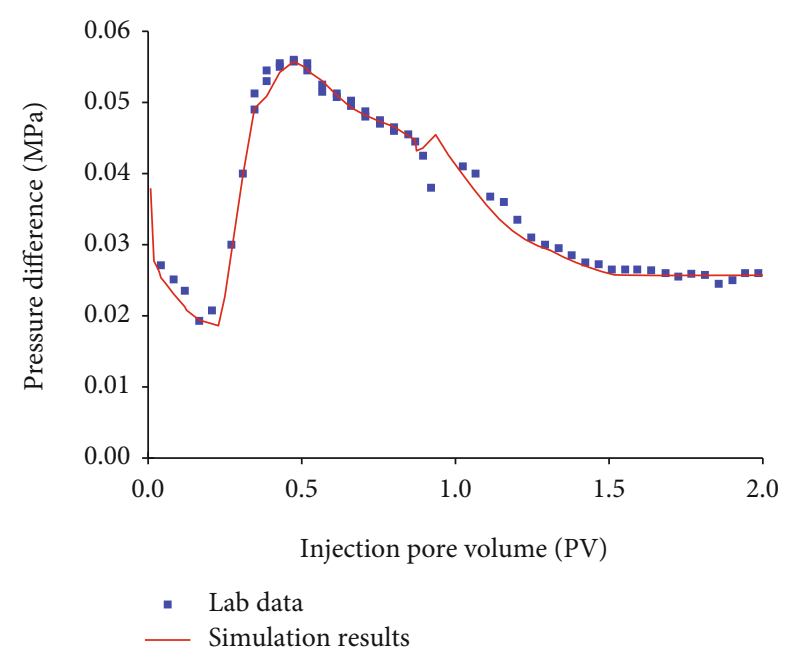

Figure 3: Comparison of pressure difference between experiment data and model calculation.

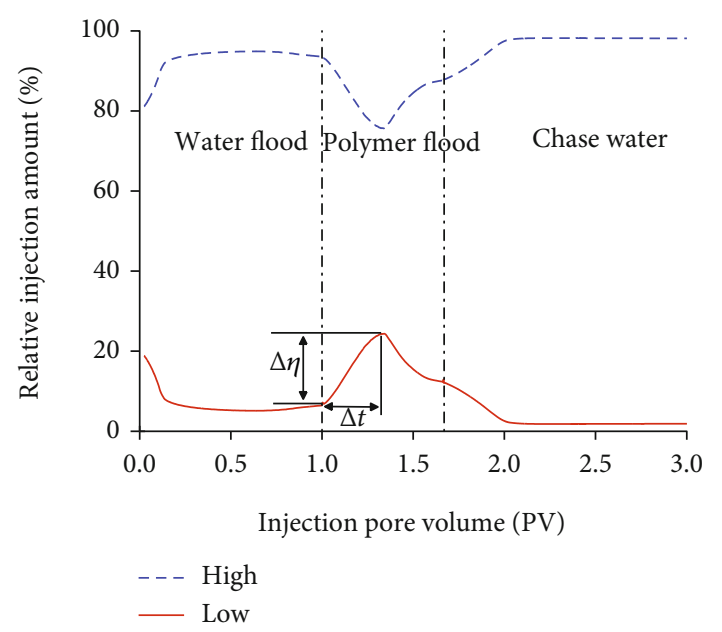

FIGURE 4: Injection conformance behavior as a function of the injection pore volume.

specified as the real reservoir data of the oil field, and the oil viscosity is $70.0 \mathrm{mPa} \cdot \mathrm{s}$ at reservoir conditions; (4) as for the injected polymer solution properties, its viscosity is $8.0 \mathrm{mPa} \cdot \mathrm{s}$ at the concentration of $1750 \mathrm{mg} / \mathrm{L}$, and the residual resistance factor is 1.6; (5) the injection rate is $0.06 \mathrm{PV}$ per year, and the reservoir replacement ratio is 1.0; and (6) for the injection sequence, firstly, water floods for 1.0 PV; then, polymer floods for $0.67 \mathrm{PV}$ and finally turns to chase water flooding.

3.1. Mechanisms on Injection Conformance Reversion. The injection conformance is shown in Figure 4. The relative injection amount of the low permeable layer firstly decreases quickly and goes stable in the water flooding stage and increases linearly when polymer injection starts and then turns to decrease later. Generally, the injection conformance displays a V-type curve. The mechanisms and its change law on the conformance reversion during polymer flooding are explored in the following.
The relative injection amount of the low permeable layer during polymer flooding and its derivative are

$$
\begin{aligned}
f_{1} & =\frac{\bar{\lambda}_{2}^{-1}}{M \bar{\lambda}_{1}^{-1}+\bar{\lambda}_{2}^{-1}}, \\
f_{1}^{\prime} & =\left(\frac{\bar{\lambda}_{2}^{-1}}{M \bar{\lambda}_{1}^{-1}+\bar{\lambda}_{2}^{-1}}\right)^{\prime} \\
& =\frac{M \bar{\lambda}_{1}^{-1} \bar{\lambda}_{2}^{-1}}{\left(M \bar{\lambda}_{1}^{-1}+\bar{\lambda}_{2}^{-1}\right)^{2}}\left[\frac{\left(\bar{\lambda}_{2}^{-1}\right)^{\prime}}{\bar{\lambda}_{2}^{-1}}-\frac{\left(\bar{\lambda}_{1}^{-1}\right)^{\prime}}{\bar{\lambda}_{1}^{-1}}\right],
\end{aligned}
$$

where $M$ is the formation coefficient ratio of the high permeable zone to the low permeable zone; subscripts 1 and 2 indicate the low permeable zone and high permeable zone. Eqs. (23) and (24) show that the relative injection amount depends on flow resistance force of each layer, and its trend depends on the variation ratio of flow resistance force. There are three scenarios:

$$
\begin{gathered}
\text { when } \frac{\left(\bar{\lambda}_{2}^{-1}\right)^{\prime}}{\bar{\lambda}_{2}^{-1}}>\frac{\left(\bar{\lambda}_{1}^{-1}\right)^{\prime}}{\bar{\lambda}_{1}^{-1}}, f_{1}^{\prime}>0 \text {, then the relative } \\
\text { sunction of the low permeability zone increases, }
\end{gathered}
$$

$$
\text { when } \frac{\left(\bar{\lambda}_{2}^{-1}\right)^{\prime}}{\bar{\lambda}_{2}^{-1}}=\frac{\left(\bar{\lambda}_{1}^{-1}\right)^{\prime}}{\bar{\lambda}_{1}^{-1}}, f_{1}^{\prime}=0 \text {, then conformance }
$$

$$
\text { when } \frac{\left(\bar{\lambda}_{2}^{-1}\right)^{\prime}}{\bar{\lambda}_{2}^{-1}}<\frac{\left(\bar{\lambda}_{1}^{-1}\right)^{\prime}}{\bar{\lambda}_{1}^{-1}}, f_{1}{ }^{\prime}<0 \text {, then the relative }
$$

sunction of low the permeability zone decreases.

The flow resistance force of each layer and its variation ratio are shown in Figure 5. At the early stage of polymer flooding, the polymer is preferentially injected into the high permeable layer, which leads to a fast and dramatical increment in resistance force for the high permeable layer but slow and moderate for the low permeable layer (see Figure 5(a)); thus, $\left(\bar{\lambda}_{2}^{-1}\right)^{\prime} / \bar{\lambda}_{2}^{-1}>\left(\bar{\lambda}_{1}^{-1}\right)^{\prime} / \bar{\lambda}_{1}^{-1}$ and the relative injection amount of the low permeable layer increases; as more polymer solution is injected into the low permeable layer, its growth ratio increases and the opposite situation takes place for the high permeable layer, which reduces the difference on resistance force variation and slows the rise velocity of water injection; the conformance reversion takes place when $\left(\bar{\lambda}_{2}^{-1}\right)^{\prime} / \bar{\lambda}_{2}^{-1}=\left(\bar{\lambda}_{1}^{-1}\right)^{\prime} / \bar{\lambda}_{1}^{-1}$. After that, the growth ratio of force decreases fast for the high permeable layer, but relatively moderate for the low permeable layer (see Figure 5(b)), which results in that $\left(\bar{\lambda}_{2}^{-1}\right)^{\prime} / \bar{\lambda}_{2}^{-1}<\left(\bar{\lambda}_{1}^{-1}\right)^{\prime} /$ $\bar{\lambda}_{1}^{-1}$, and the relative injection amount of the low permeable layer decreases. In general, the difference in the injection 


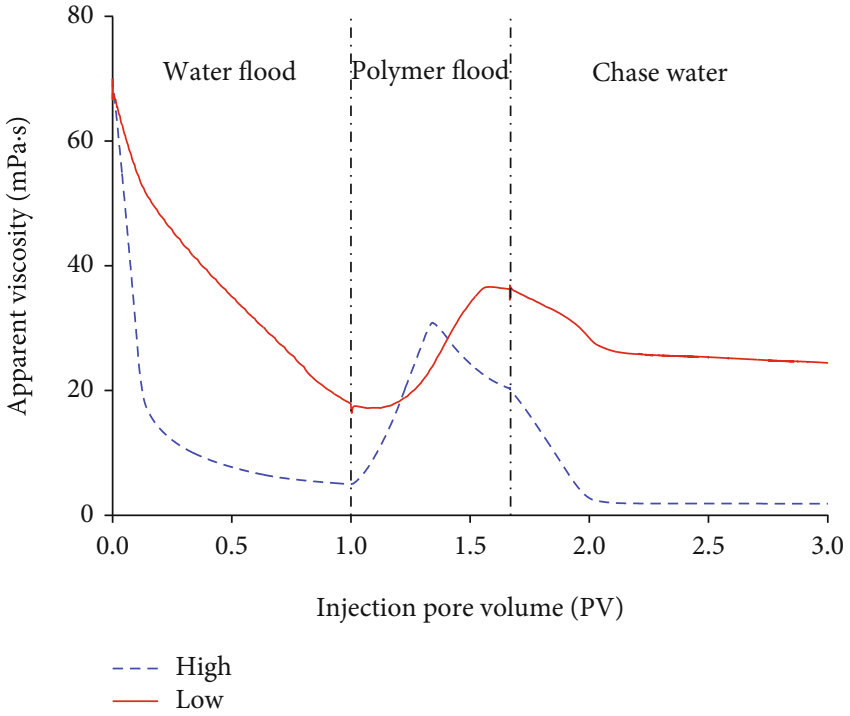

(a) Apparent viscosity

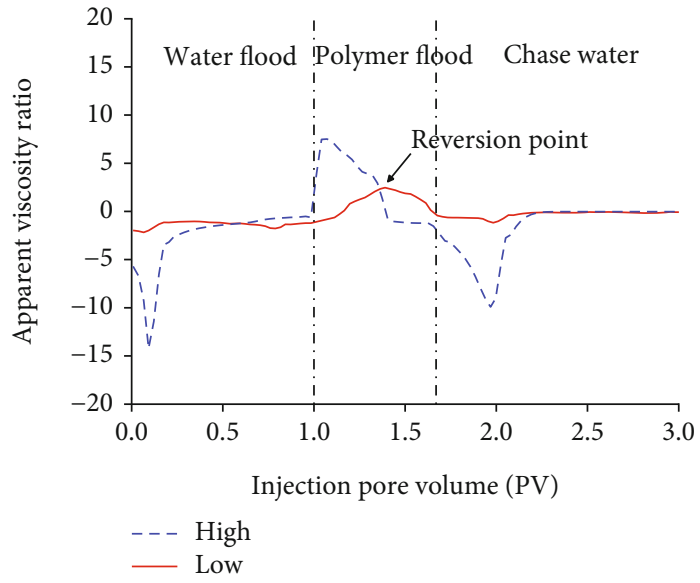

(b) Apparent viscosity alteration rate

FIgURE 5: Apparent viscosity and its alteration rate of each layer as a function of the injection pore volume.

ability of layers creates different alternations on flow resistance force, which reacts upon the injection ability and results in dynamic redistribution of injection between layers. The injection conformance reversion takes place when the relative alteration rate of flow resistance force tends to be the same.

3.2. Impact Factor Analysis. According to the injection conformance mathematical model of a heterogeneous heavy-oil reservoir, the impact factors on the injection conformance include oil viscosity, permeability contrast, porosity ratio and net thickness ratio of different layers, and polymer concentration.

Two parameters are introduced to quantitatively characterize the injection conformance reversion phenomenon, i.e., reversion timing and reversion depth. The former is defined as the polymer solution injection volume at the peak value of the relative injection amount of the low permeable layer, and its unit is unusually the pore volume coefficient; the latter indicates the difference between the peak value during polymer flooding and the value at polymer flooding start-up of the low permeable layer of the relative injection amount (see Figure 4).

3.2.1. Oil Viscosity. The injection conformance behavior for reservoirs with different oil viscosities is shown in Figure 6. When the oil viscosity ranges from $5 \mathrm{mPa} \cdot \mathrm{s}$ to $70 \mathrm{mPa} \cdot \mathrm{s}$, the injection conformance shape tends to V-type from U-type as oil viscosity increases, and the relative injection amount of the low permeable layer and its peak value decreases, as well as the reversion timing is advanced. Therefore, the total injection volume reduces. It can be seen that the ability of polymer flooding to improve volumetric sweep decreases with the increase of oil viscosity. Heavy oil makes its injection conformance tend to V-type, which usually creates lowefficiency circulation of polymer in the high permeable layer and low recovery of the low permeable layer.

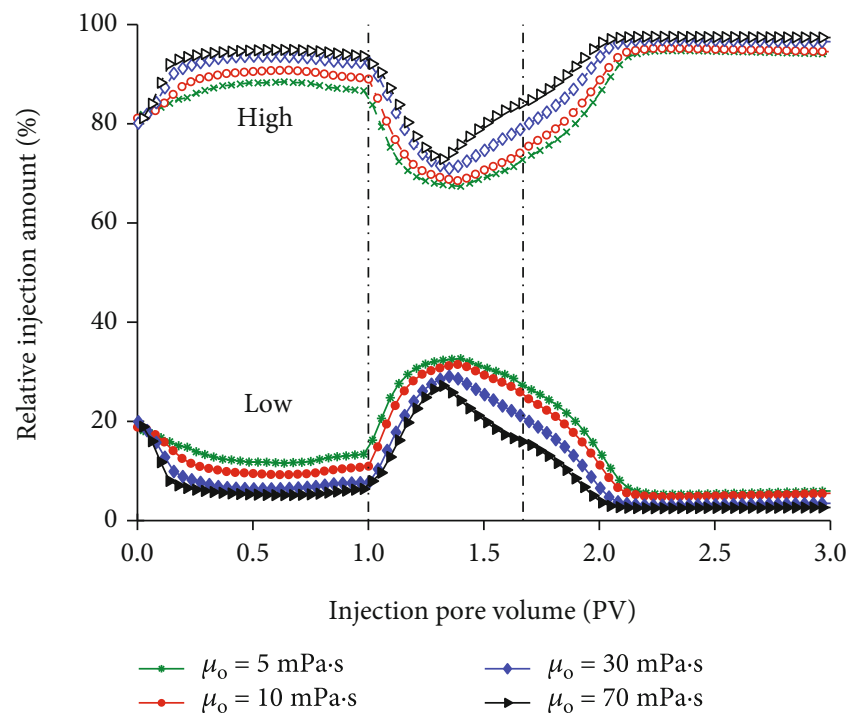

Figure 6: Injection conformance behavior for reservoirs with different oil viscosities.

3.2.2. Permeability Contrast. The injection conformance behavior for reservoirs with different permeability contrast is shown in Figure 7. When the permeability contrast ranges from 4 to 10 , as its value increases, the relative injection amount of the low permeable layer and its reversion depth significantly decreases, as well as the reversion timing is advanced. It can be seen that the ability of polymer flooding to improve the volumetric sweep decreases with the increase of permeability contrast.

3.2.3. Porosity Ratio of Different Layers. Given that the porosity of the high permeable layer is fixed at 0.32 , the porosity of the low permeable layer is changed to $0.08,0.16,0.24$, and 0.32 . The corresponding porosity ratio of high to low permeable zones is 4.0,3.0, 2.0, and 1.0. The injection conformance 


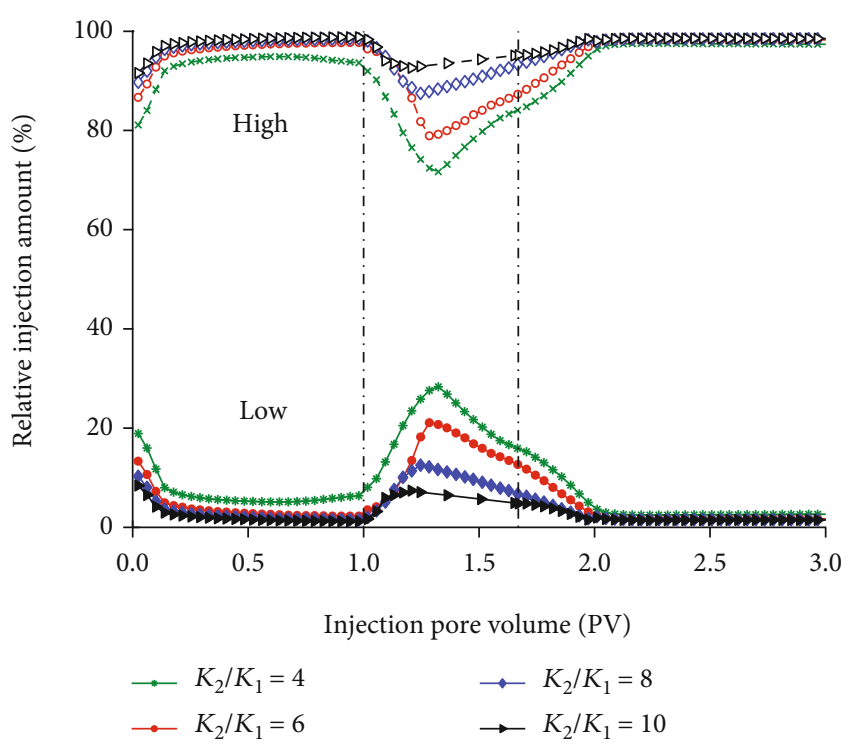

Figure 7: Injection conformance behavior for reservoirs with different permeability contrast.

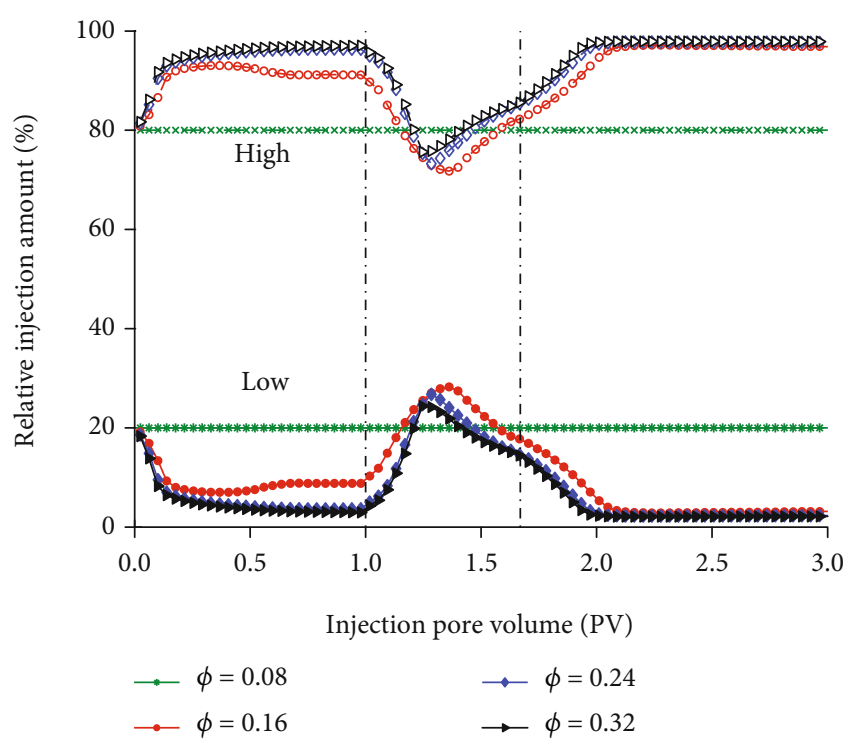

FIGURE 8: Injection conformance behavior for reservoirs with different porosity ratios of low to high permeable zones.

behavior for reservoirs with different porosity ratios is shown in Figure 8. As the porosity of the low permeable layer decreases, its relative injection amount and peak value increase, as well as the reversion timing is advanced. It is worth noting that the relative injection amount remains unchanged throughout the entire development procedure when the porosity is 0.08 , and the reversion disappears. The reason is that when $K_{1} / \phi_{1}=K_{2} / \phi_{2}$, the flow resistance force term of different layers is always the same according to Eq. (6), i.e., $\bar{\lambda}_{j}^{-1}\left(Q_{j}\right) d Q_{j}=\bar{\lambda}_{i}^{-1}\left(Q_{i}\right) d Q_{i}$. Because apparent viscosity $\bar{\lambda}^{-1}$ has a nonlinear and complicated relationship to injection pore volume $Q$, thus $\bar{\lambda}_{j}^{-1}\left(Q_{j}\right)=\bar{\lambda}_{i}^{-1}\left(Q_{i}\right)$, and then, $f_{i}=K_{i} H_{i} / \sum K_{i} H_{i}$, which means that the relative injection

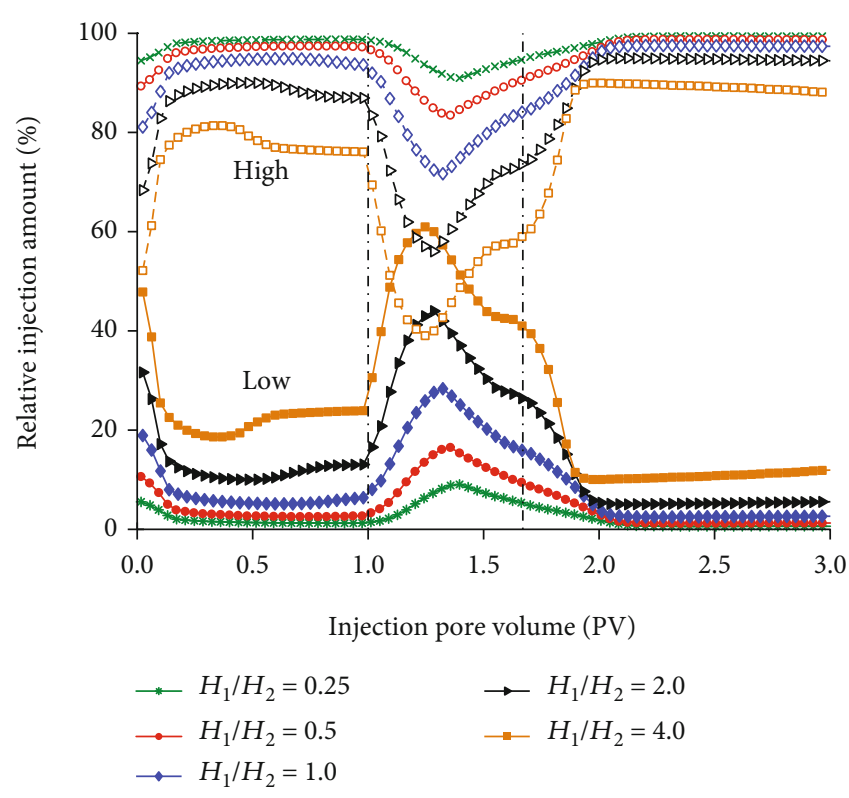

FIGURE 9: Injection conformance behavior for reservoirs with different net thickness ratios of low to high permeable zones.

amount of each layer remains fixed and is proportional to its formation coefficient. Therefore, given the permeability contrast, the lower the porosity of the low permeable layer, the more favorable it is to realize the balanced advance, as well as the lower the reversion depth and the later the reversion timing.

3.2.4. Net Thickness Ratio of Different Layers. The injection conformance behavior for reservoirs with different net thickness ratios of low to high permeable zones is shown in Figure 9. When the net thickness ratio ranges from 0.25 to 4.0 , as the relative thickness increases, the difference of the formation coefficient between layers decreases, both the relative injection amount of the low permeable layer and reversion depth significantly increase, and the reversion timing is advanced. The peak value of the relative injection amount is $60 \%$ when the net thickness ratio equals to 4 , which is larger than the high permeable zone with a value of $40 \%$.

3.2.5. Polymer Concentration. The injection conformance behavior for reservoirs with different polymer concentrations is shown in Figure 10. When the polymer concentration ranges from $800 \mathrm{mg} / \mathrm{L}$ to $2300 \mathrm{mg} / \mathrm{L}$, as the polymer concentration or viscosity increases, the relative injection amount of the low permeable layer significantly increases, but the reversion timing is advanced from $0.49 \mathrm{PV}$ to $0.26 \mathrm{PV}$, and the injection conformance shape tends to V-type from U-type. It can be seen that the ability of polymer flooding to improve the volumetric sweep increases with the increase of polymer concentration. Therefore, more polymer can be injected into the low permeable layer to receive additional oil recovery by reasonably increasing polymer concentration.

3.2.6. Polymer Flooding Timing. The injection conformance behavior for reservoirs with different polymer flooding 


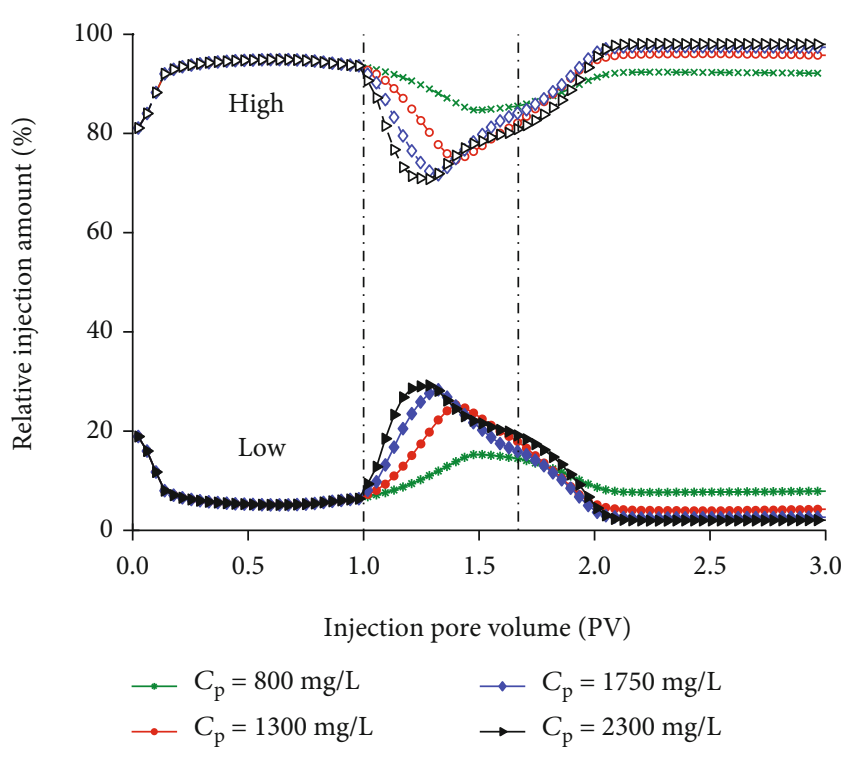

Figure 10: Injection conformance behavior for reservoirs with different polymer concentrations.

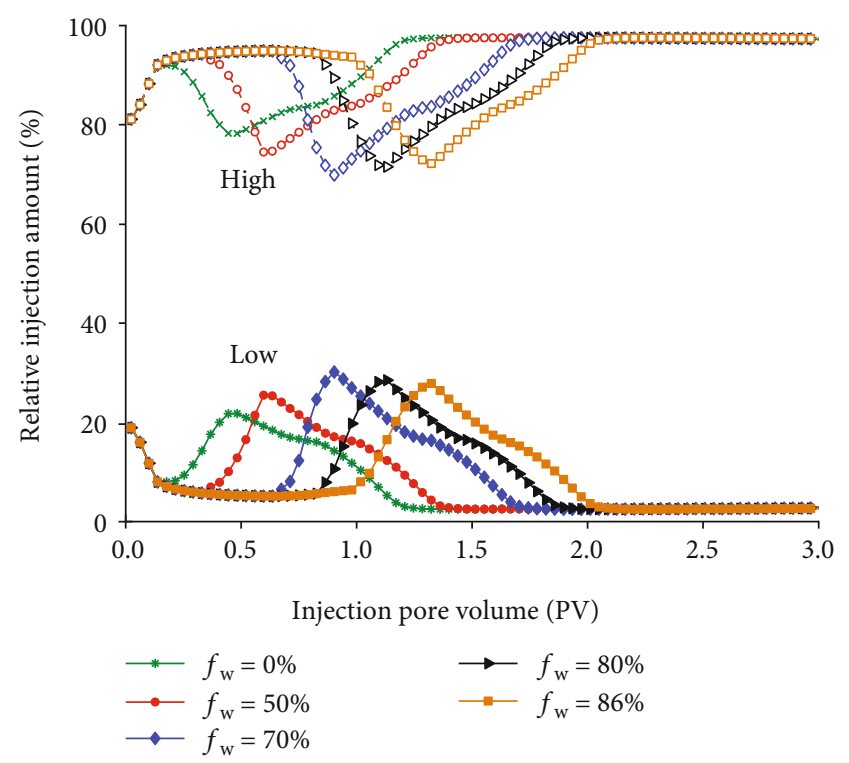

FIGURE 11: Injection conformance behavior for reservoirs with different polymer flooding timing.

timing is shown in Figure 11. When the polymer flooding starts at the water cut from $0 \%$ to $86 \%$, the injection conformance of the low permeable layer turns to be lanky from dumpy as the polymer flooding implementation is delayed. Its peak value firstly increases significantly and then falls mildly, and the reversion timing is firstly advanced from $0.30 \mathrm{PV}$ to $0.24 \mathrm{PV}$ and then delayed to $0.32 \mathrm{PV}$. The reason is that the oil phase dominates the total fluid flow capacity for earlier polymer flooding, and it contains the ability of a polymer to alter the flow resistance between layers, which results in a smaller peak value of injection conformance for lower permeable layers. The flood front can propagate more evenly by choosing reasonable polymer flooding timing.

\section{Conclusions}

(1) One mathematical model to predicate injection conformance behavior is constructed for heterogeneous reservoirs based on the Buckley-Leverett function, which can fast quantitatively characterize conformance reversion in offshore heavy-oil reservoirs

(2) Mechanisms on the injection conformance reversion during polymer flooding of offshore heterogeneous heavy-oil reservoirs are explored. A polymer is preferentially injected into the high permeable layer, which leads to rapid and dramatical increment of its flow resistance force but slow and moderate for the low permeable layer; thus, the relative injection amount of the low permeable layer firstly increases. It in turn makes the resistance force increase more and more quickly for the lower permeable layer but more and more mildly for the high permeable layer, which reduces the difference in resistance force variation between layers. The conformance reversion takes place when the variation ratio of different layers is equal. After that, the variation ratio of the lower permeable layer is larger than that of the high permeable layer; then, relative injection of the low permeable layer falls

(3) The properties of offshore polymer flooding, i.e., relative high permeability contrast, large viscosity, and earlier polymer flooding, make the injection conformance behavior tend to V-type and easily create low-efficiency circulation of polymer in the high permeable layer and low recovery of the low permeable layer

(4) As oil viscosity or permeability contrast increases, or relative thickness of the low permeable layer or polymer concentration decreases, the peak value and scope of conformance reversion decrease and reversion timing becomes earlier, which lower the liquid suction of the low permeable zone. In addition, as porosity of the low permeable layer decreases, the reversion timing is delayed and its relative injection amount increases. The conformance reversion can even disappear when the porosity ratio reaches the permeability contrast

\section{Data Availability}

The (excel) data used to support the findings of this study are included within the article.

\section{Conflicts of Interest}

The authors declare that they have no conflicts of interest.

\section{Acknowledgments}

The authors are grateful for the financial support from the State Major Science and Technology Special Project of China during the 13th Five-Year Plan (Grant No. 
2016ZX05025-003), the National Natural Science Foundation of China (Grant No. 52074347), and the CNOOC Major Science and Technology Project (Grant No. CNOOC-KJ135ZDXM36TJ02ZY).

\section{References}

[1] X. Zhang, F. Sun, J. Hou, X. Kang, X. Xie, and S. Jiang, "Quantitative characterization of production indices for polymer flooding of offshore heavy oils," Acta Petrolei Sinica, vol. 34, no. 4, pp. 727-732, 2013.

[2] W. Zheng, X. Zhang, F. Chen, H. Jiang, and M. Chen, "Effect of polymer flooding occasion on development result of Bohai oilfield," Journal of Xi'an Shiyou University (Natural Science Edition), vol. 30, no. 2, pp. 60-64, 2015.

[3] S. Zhou, M. Han, W. Xiang, J. Zhang, W. Zhou, and W. Jiang, "Application of EOR technology by means of polymer flooding in Bohai oilfields," China Offshore Oil and Gas, vol. 18, no. 6, pp. 386-389, 2006.

[4] D. M. Wang, J. C. Cheng, J. Z. Wu, and G. Wang, “Application of polymer flooding technology in Daqing Oilfield," Acta Petrolei Sinica, vol. 26, no. 1, pp. 74-78, 2005.

[5] H. Sun, "Practice and understanding on tertiary recovery in Shengli oilfield," Petroleum Exploration and Development, vol. 33, no. 3, pp. 262-266, 2006.

[6] D. Wang, D. Han, W. Hou, R. Cao, and L. Wu, "Types and changing laws of profile reversal during polymer flooding," Petroleum Geology \& Oilfield Development in Daqing, vol. 26, no. 4, pp. 96-99, 2007.

[7] H. Wang, J. Wang, X. Wang et al., "Research on early polymer flooding characteristics in offshore oilfield," Science Techonology and Engineering, vol. 19, no. 15, pp. 131-135, 2015.

[8] H. Luo, K. K. Mohanty, and M. Delshad, "Modeling and upscaling unstable water and polymer floods: dynamic characterization of the effective viscous fingering," SPE Reservoir Evaluation and Engineering, vol. 20, no. 4, pp. 0779-0794, 2017.

[9] H. Peihui, L. Haibo, H. Xu, C. Ruibo, Z. Yuwei, and L. Xiaoyang, "Alternative injection and its seepage mechanism of polymer flooding in heterogeneous reservoirs," in SPE Asia Pacific Enhanced Oil Recovery Conference, Kuala Lumpur, Malaysia, 11-13 Aug 2015.

[10] R. Cao, X. Wang, and P. Han, "Multi-slug alternative injection method and field application of polymer flooding," Petroleum Geology and Recovery Efficiency, vol. 19, no. 3, pp. 71-75, 2012.

[11] R. Cao, "Laboratory research on section reversion mechanism of polymer flooding," Petroleum Geology and Recovery Efficiency, vol. 16, no. 4, pp. 71-73, 2009.

[12] R. Cao, P. Han, and W. Hou, "Section inversion rules and inversion mechanism of polymer flooding," Acta Petrolei Sinica, vol. 30, no. 2, pp. 267-270, 2009.

[13] D. Wang, R. S. Seright, K. P. M. S. Let, K. Bhoendie, and W. R. Paidin, "Compaction and dilation effects on polymer flood performance," in SPE Europec featured at 79th EAGE Conference and Exhibition, Paris, France, 12-15 June 2017.

[14] R. B. Cao, P. H. Han, and G. Sun, "Oil displacement efficiency evaluation of variable viscosity polymer slug alternative injection," Oil drilling \& Production Technology, vol. 33, no. 6, pp. 88-91, 2011.

[15] Z. J. WEI, X. D. KANG, X. S. ZHANG, and J. ZHANG, “A black-oil-based multi-component model for polymer flood- ing," SCIENTIA SINICA Technologica, vol. 48, no. 4, pp. 415-423, 2018.

[16] S. Gao, Z. Jiang, K. Zhang et al., "High concentration polymer flooding field test with well infilling to change fluid flowing direction after polymer flooding," in SPE EOR Conference at Oil and Gas West Asia, Muscat, Oman, 21-23 march 2016.

[17] S. E. Buckley and M. C. Levertt, "Mechanism of fluid displacement in sands," Transactions of the AIME, vol. 46, no. 1, pp. 107-116, 1942.

[18] D. Deniz and D. Birol, "Analytical solution of nonisothermal Buckley-Leverett flow including tracers," SPE Reservoir Evaluation and Engineering, vol. 11, no. 13, pp. 65-74, 2008.

[19] L. Deng and M. King, "Capillary corrections to BuckleyLeverett flow," in SPE Annual Technical Conference and Exhibition, Houston, Texas, USA, Sep 28-30 2015.

[20] E. Mirsayanova, A. Cheremisin, M. Evseeva, and A. Cheremisin, "Numerical simulation of polymer flooding," in SPE Russian Petroleum Technology Conference, Russia, 2629 October 2020.

[21] D. G. Sabirov, R. A. Demenev, K. D. Isakov, I. R. Ilyasov, A. G. Orlov, and N. A. Glushchenko, "Reservoir simulation of polymer flooding: challenges and current results," in SPE Russian Petroleum Technology Conference, Russia, 26-29 October 2020.

[22] R. S. Seright, D. M. Wang, N. Lerner, A. Nguyen, J. Sabid, and R. Tochor, "Beneficial relative permeabilities for polymer flooding," in SPE Improved Oil Recovery Conference, Tulsa, Oklahoma, USA, 14-18 April 2018. 